\title{
'Rehab' helps errant researchers return to the lab
}

\section{As cases of misconduct rise, ethicists test an approach for reforming offenders.}

\section{BY DANIEL CRESSEY}

$\mathrm{O}$ n 8 January, four health scientists accused of research misconduct are expected to file into a room at Saint Louis University in Missouri to conduct an experiment: can they be rehabilitated? Using pseudonyms if they wish, the four will discuss what they did wrong, why they did it and how they might stop it from happening again - all in an effort to see if they can re-enter the scientific mainstream.

With the rapid growth of misconduct cases, some scientists are worried that preventative training in research ethics might not be enough. Nor will it be possible simply to dismiss all violators from science. Scientific rehabilitation, they say, will have to become a necessary tool for research-integrity offices.

"Sometimes these are very talented researchers," says James DuBois, an ethicist at Saint Louis University, who leads the rehab programme, called RePAIR (Restoring Professionalism and Integrity in Research). "We believe that if we can equip them with certain skills, they can return to the field as very productive individuals."

DuBois could have plenty of customers on the way. The US Office of Research Integrity (ORI) in Rockville, Maryland, received 419 allegations of misconduct at institutions in $2012-$ nearly double the number in 2011, says David Wright, director of the ORI. Wright puts much of this down to software that has made it easier for watchdogs to detect possible plagiarism or image manipulation in publications. "We now get allegations from all over the world," he says.

As the pursuit of misconduct increases, there has been less focus on how to deal with guilty scientists. Lauran Qualkenbush, director of the research-integrity office at Northwestern University in Chicago, says that there is a gap between harsh penalties for misconduct - such as bans from receiving government funding and lighter punishments such as taking a short online ethics course and getting a letter of reprimand. "It's not always black and white," she says. "These are people we feel could be valuable members of our faculty and community."

DuBois aims to fill that gap. Although remedial courses have been available for physicians for more than a decade - with many returning to medicine to forge successful careers - DuBois says that RePAIR is the first such programme for researchers. Developed

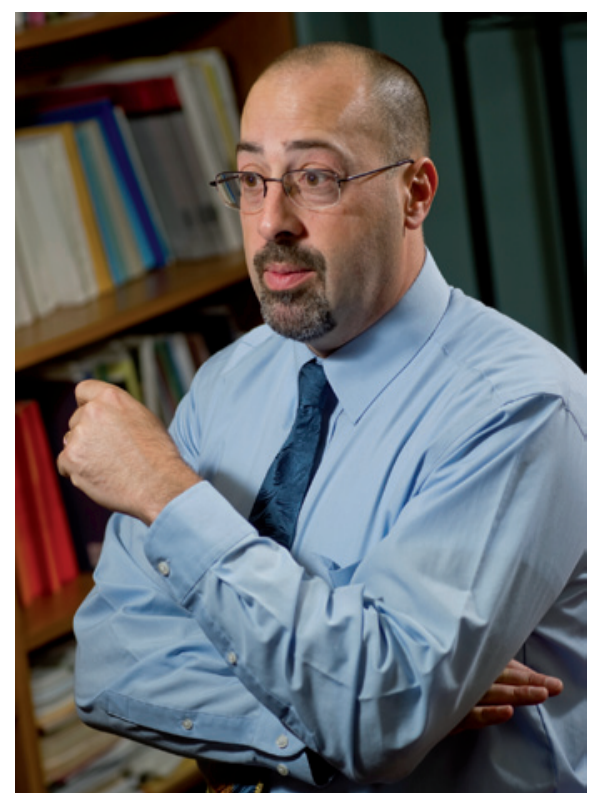

James Dubois hopes that his programme will let wayward researchers back into the scientific fold.

with a US $\$ 500,000$ grant from the National Institutes of Health, the three-day course costs $\$ 3,000$ per participant, or half that if host institutions sign up as partners for $\$ 1,500$ a year.

Day one of the course focuses on 'self-serving biases' - in which people take credit for success but blame external factors for failures - and on getting participants to examine the factors that have led to them breach the accepted rules of research. The second day gets participants to talk about what they did wrong, and focuses on skills to promote ethical decision-making, such as what they could have done differently in their own research. On the final day, professional management plans are drawn up for each participant to try to prevent them falling back into bad habits, with follow-up interviews taking place in the weeks after the course. If participants complete all of these activities to the satisfaction of the RePAIR team, a certificate of completion is sent to their institution.

Last year, DuBois conducted a survey of 129 US institutions and found that most were investigating between three and five cases of wrongdoing per year. He says that, so far, around six universities, including Northwestern, have signed up as partners in the programme.

Some ethicists are unsure how effective such rehab will be. Nicholas Steneck, an ethicist at the University of Michigan in Ann Arbor, is broadly supportive of the goals of RePAIR, but says that he wonders if the money might be better spent on measures that prevent misconduct.

Although the ORI is not endorsing RePAIR specifically, Wright says that his previous job as a research-integrity officer at Michigan State University in East Lansing has made him well aware of the need for such a programme especially for researchers who have committed low-level misconduct, such as failing to disclose a conflict of interest. "What do you do with them to make them whole as members of the research community, so they're not just pariahs in their community forever? My view is if you're not going to fire somebody, there ought to be a way for them to re-establish themselves."

Wright says it is too early to say if DuBois and colleagues' programme will work, but thinks that it is "a worthy effort and I salute them".

Scrutiny of misconduct is also growing rapidly in Europe. According to Steneck, who consults for Epigeum, a London-based company that provides training on research integrity, that is because the definition of misconduct is broadening beyond falsification, fabrication and plagiarism. 'Grey area' cases such as self-plagiarism and duplicate publication are increasingly attracting attention, he says. However, the extent of misconduct is harder to establish in Europe than in the United States, because the overarching European Union research-funding system - as well as those of individual countries like the United Kingdom - lack an official investigatory body similar to the ORI. This means that responsibility for dealing with misconduct can fall solely on individual institutions.

A session of the RePAIR programme in May has already been advertised, and DuBois eventually hopes to run the course for up to ten people at a time.

"A lot of people will say to me, "These are bad apples - you're not going to reach them," he says. "My sense is that may be true of $10 \%$, $15 \%$, maybe even $20 \%$, but I do believe that we can make a difference in the lives of the vast majority." -

\section{CORRECTION}

The News Feature 'Nature's 10' (Nature 492, 335-343; 2012) gave the wrong age for Jun Wang. He is 36 , not 34 . 